\title{
New EANM paediatric dosage card: optimization of F-18 FDG-administered activities
}

\author{
Gilles Metrard • Hélène Besse • Diane Darsin-Bettinger • \\ Sofiane Mouzoune $\cdot$ Sabine Gauvain
}

Received: 16 April 2014 / Accepted: 16 May 2014 / Published online: 4 June 2014

(C) Springer-Verlag Berlin Heidelberg 2014

\section{Dear Sir,}

We read with interest the recently published article with the new EANM paediatric dosage card [1].

However, we were surprised by the $18 \mathrm{~F}-\mathrm{FDG}$ activity in PET. As a matter of fact, "F-18 FDG (2D)" was changed to "FDG-PET torso" and "F-18 FDG (3D)" to "FDG-PET brain" with respectively the same parameters, but the $2 \mathrm{D}$ and $3 \mathrm{D}$ modes referred to a technology and not to an anatomical region. In the 2007-2008 dosage card [2, 3], the EANM paediatrics committee recommended using the most efficient 3D mode with lower activity than 2D PET.

In the new paediatric dosage card, the activity does not appear to be significantly higher than the North American consensus guideline (SNMMI guideline) [4]. But the comparison was made with the higher value of the SNMMI guideline activity range $(5.2 \mathrm{MBq} / \mathrm{kg})$. However, a low end of activity range should be considered for smaller patients, which is often the case in children.

In a referenced article [5], Alessio et al. proposed an activity of $3.2 \mathrm{MBq} / \mathrm{kg}$ for the optimal paediatric PET close to the minimal level of $3.7 \mathrm{MBq} / \mathrm{kg}$ proposed by the SNMMI guideline and F-18 FDG (3D) 2008 EANM dosage card.

As a result, the new EANM "FDG-PET torso" recommendations are more than $80 \%$ higher than the lower activity recommended by the SNMMI guideline $(3.7 \mathrm{MBq} / \mathrm{kg})$.
2D PET is now a minority in the commonly used PET, and most nuclear medicine departments use the lowest "F-18 FDG (3D)" activity for whole-body and/or total-body scanning without any impact on quality, as reported since 2008.

We fully appreciate the considerable work accomplished by the EANM/SNMMI Paediatric Dosage Harmonization Working Group, but we think that a better activity optimization is possible if "FDG-PET torso" used the same parameters as the old F-18 FDG (3D) and new "FDG-PET brain".

\section{References}

1. Lassmann M, Treves ST. Paediatric radiopharmaceutical administration: harmonization of the 2007 EANM paediatric dosage card (version 1.5.2008) and the 2010 North American consensus guidelines. Eur J Nucl Med Mol Imaging. 2014;41(5):1036-41.

2. Lassmann M, Biassoni L, Monsieurs M, Franzius C, Jacobs F. The new EANM paediatric dosage card. Eur J Nucl Med Mol Imaging. 2007;34(5):796-8.

3. Lassmann M, Biassoni L, Monsieurs M, Franzius C. The new EANM paediatric dosage card: additional notes with respect to F-18. Eur J Nucl Med Mol Imaging. 2008;35(9):1666-8.

4. Gelfand MJ, Parisi MT, Treves ST. Pediatric radiopharmaceutical administered doses: 2010 North American consensus guidelines. J Nucl Med. 2011;52(2):318-22.

5. Alessio AM, Sammer M, Phillips GS, Manchanda V, Mohr BC, Parisi MT. Evaluation of optimal acquisition duration or injected activity for pediatric 18F-FDG PET/CT. J Nucl Med. 2011;52(7):1028-34.

A reply to these comments can be found at doi: 10.1007/s00259-014-2817-4.

G. Metrard $(\bowtie) \cdot H$. Besse $\cdot$ D. Darsin-Bettinger $\cdot$ S. Mouzoune •

S. Gauvain

Orleans Hospital, 14, avenue de l'hôpital, 45000 Orleans, France

e-mail: gilles.metrard@chr-orleans.fr 